\title{
Syringohydromyelia in association with syringobulbia and syringocephaly: case report
}

\author{
Arnold H. Menezes, MD, ${ }^{1}$ Jeremy D. W. Greenlee, MD, ${ }^{1}$ Reid A. Longmuir, MD, ${ }^{2}$ \\ Daniel R. Hansen, MD,' and Kingsley Abode-lyamah, MD'1 \\ ${ }^{1}$ Department of Neurosurgery and 2Department of Ophthalmology, Division of Neuro-Ophthalmology, University of lowa Hospitals \\ and Clinics, University of lowa Carver College of Medicine, lowa City, lowa
}

\begin{abstract}
The authors present the case of a 14-year-old boy with holocord syringohydromyelia extending into the brainstem, cerebral peduncle, internal capsule, and cerebral cortex. At the posterior fossa exploration, an opaque thickened arachnoid with occlusion of the foramen of Magendie was encountered. Careful documentation of postoperative regression of the syringocephaly, syringobulbia, and syringohydromyelia was made. The pathophysiology is discussed.
\end{abstract}

http://thejns.org/doi/abs/10.3171/2014.11.PEDS14189

KEY WORDS syringomesencephaly; syringopontia; Chiari malformation; birth trauma; surgery; congenital

$\mathrm{S}$ YRINGOBULBIA is a rare entity whereby a slit-like fluid cavity is present in the brainstem. ${ }^{33,34}$ This condition is most frequently associated with hindbrain abnormalities, such as Chiari malformation Type I (CM-I), as well as neoplasms of the posterior fossa and spinal canal, but can occur in isolation, such as with previous meningitis. ${ }^{11,16-18,26,28,31}$ Syringobulbia has also been reported with CM-II and myelodysplasia. 4,6,37 With the advent of MRI, identifying the posterior fossa pathology and syringohydromyelia became much easier than in the pre-MRI era. In 1997 Afifi and Menezes described a case of holocord syringohydromyelia with rostral extension into the brainstem and reviewed the literature. ${ }^{1}$ Subsequently, Greenlee et al. identified 6 cases of syringobulbia in a pediatric population of 177 patients with CM-I abnormality and also covered the literature. ${ }^{7}$

In even more rare cases, syrinx cavities can extend further rostral into the neuraxis, from the medulla (syringobulbia), up into the pons (syringopontia), midbrain (syringomesencephaly), and cerebrum (syringocephaly). Our understanding of syringobulbia with extension into the cerebral cortex dates back to pathological studies by Spiller in $1906 .{ }^{29}$ Since then, an additional 9 cases of syringoceph- aly have been reported and encompass varying degrees of syrinx involvement of the basal ganglia, internal capsule, centrum semiovale, and cerebral cortex. . $3,5,11,13,20,23,24,35^{2}$ Here, we present the case of a 14 -year-old boy with holocord syringohydromyelia extending into the brainstem, right cerebral peduncle, and onward into the internal capsule to the cerebral cortex. He underwent a posterior fossa surgical procedure and had careful MRI documentation of the regression of the various components of the abnormality.

\section{Case Report}

History and Examination

A 14-year-old boy was referred to the Pediatric Neurosurgery Service with a history of newly acquired Horner's syndrome affecting the left side and abnormal findings on MRI. His birth history was significant for a frank breech presentation at 35 weeks requiring forceps delivery. His Apgar scores were 1 and 4 at 1 and 5 minutes, respectively. He was immediately intubated because of poor ventilatory effort and was subsequently extubated on Day 2. He had poor movement of all limbs, but his arms were

ABBREVIATION CM-I = Chiari malformation Type I.

SUBMITTED April 9, 2014. ACCEPTED November 12, 2014.

INCLUDE WHEN CITING Published online March 13, 2015; DOI: 10.3171/2014.11.PEDS14189.

DISCLOSURE The authors report no conflict of interest concerning the materials or methods used in this study or the findings specified in this paper. 
more affected. Over the span of a few days, he developed a marked increase in the tone of his upper extremities. Evaluation by a pediatric neurologist indicated that these findings were consistent with spinal cord injury due to birth trauma. The patient underwent brain CT and electromyography recording of the upper and lower extremities, which were unremarkable. Laboratory and diagnostic studies, including creatine phosphokinase testing, lactate level testing, electroencephalography, and brain MRI, were also within normal limits. The child later exhibited psychomotor developmental delay with slow speech, but it improved to the point that at 2 years of age he was functioning at a normal level. The Pediatric Ophthalmology Service, which had followed him since birth, continued to monitor him for what was believed to be asymptomatic convergence insufficiency.

At the age of 14 years, the boy developed new left ptosis and anisocoria. On detailed questioning, he and his family reported that his handwriting had worsened and that he had a tendency to drop objects out of his left hand. Headaches had been present for several years, as had choking on liquids and solids. The family also noted snoring at night. An additional symptom was shortness of breath with exercise and subsequent wheezing. He described an ulcerated lesion on the dorsum of the left forearm that was slow to heal and insensitive to pain. Because of this lesion and his "constant picking on it," he had been referred to a mental health therapist.

Physical examination at the time of neurosurgical evaluation revealed appropriate mental status. He had partial ptosis of the left lid with a smaller left pupil and intact extraocular movements. Gag response and tongue motion were normal. Temperature, light touch, and pinprick sensation in the face were equal on both sides. Temperature discrimination was absent in the right and left arms. There was a chronically appearing ulceration on the dorsum of the left forearm, and sensation to pinprick was markedly reduced in the left upper extremity. There was decreased sensation to touch and pinprick in the bilateral lower extremities. He was strong in both upper and lower extremities. He hopped poorly. He was grossly hyperreflexic throughout with bilateral Hoffman and Babinski responses. Abdominal reflexes were absent. There was thoracic scoliosis with convexity to the left in the upper thoracic spine, which had not been present on a chest radiograph obtained 4 years earlier.

Because of the left ptosis and miosis, the child was further evaluated by the Pediatric Ophthalmology and Neuro-Ophthalmology Services. His apraclonidine test was positive for left-sided Horner's syndrome. Postganglionic localization was confirmed by hydroxyamphetamine testing.

Brain MRI revealed marked crowding at the foramen magnum. There was a question of tonsillar ectopia. Holocord syringohydromyelia extended from C-2 to L-1. There was a fluid-filled cavity within the medulla that extended bilaterally into the pons and vertically into the mesencephalic tegmentum through the crus cerebri to the thalamus on the right and up to the cerebral cortex (Figs. 1-3). There was no enhancement with contrast. Additional testing with polysomnography showed obstructive sleep
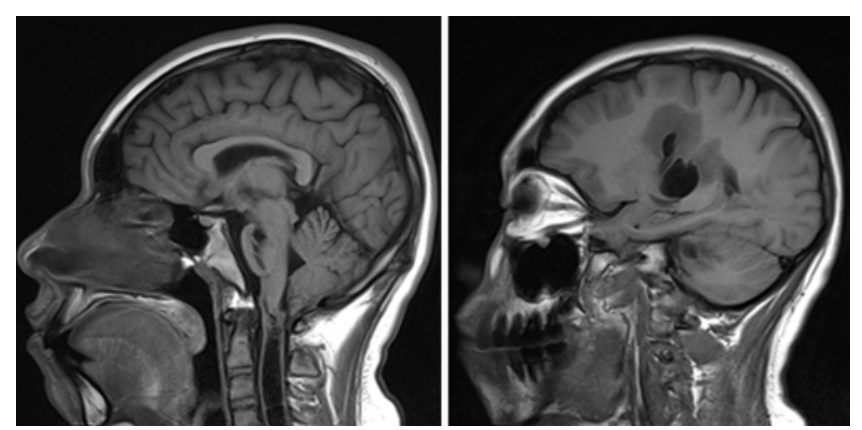

FIG. 1. Composite of midsagittal (left) and parasagittal (right) T1weighted MR images of the brain preoperatively. Note the cervical syringohydromyelia with extension into the medulla, pons, and cerebrum.

apnea. Fiberoptic laryngoscopy showed normal movement of the vocal cords, and a formal swallow study was normal.

\section{Operation}

Because of the crowded foramen magnum, the patient underwent posterior fossa craniectomy with foramen magnum decompression and partial C-1 laminectomy. On opening the dura mater, the arachnoid was white, opaque, and intensely scarred (Fig. 4A). In fact, it was thicker than the dura itself. Arachnoid adhesions were freed from the tonsils, which were separated from each other as well as the dorsal aspect of the cervicomedullary junction. The foramen of Magendie was closed with opaque arachnoid tissue and was then widely opened (Fig. 4B). The floor of the fourth ventricle was carefully inspected, and there was no visible communication with the syringobulbia. However, there was free communication into the central canal of the cervical spinal cord (Fig. 4C). We did not believe that this represented a CM-I abnormality. The cerebellar tonsils were shrunk. A cervical fascia duraplasty was made. The patient remained intubated for the first 24 hours.

\section{Postoperative Course}

Magnetic resonance imaging on postoperative Day 1 showed a marked reduction in the size of the cerebral component of the syringocephaly. There was a decrease in the width of the syringobulbia as well as the syringo-
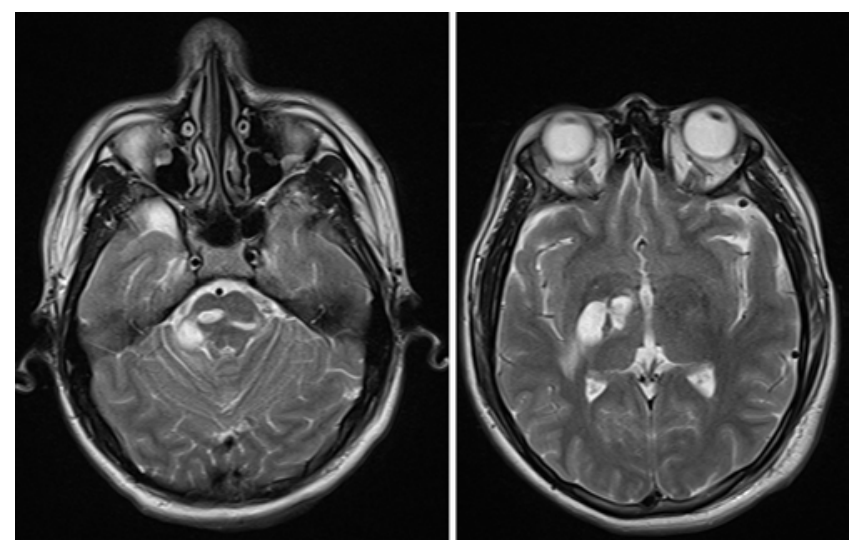

FIG. 2. Composite of preoperative axial T2-weighted MR images through the plane of the pons (left) and the basal ganglia (right). Note the bilateral pontobulbia and syringocephaly. 


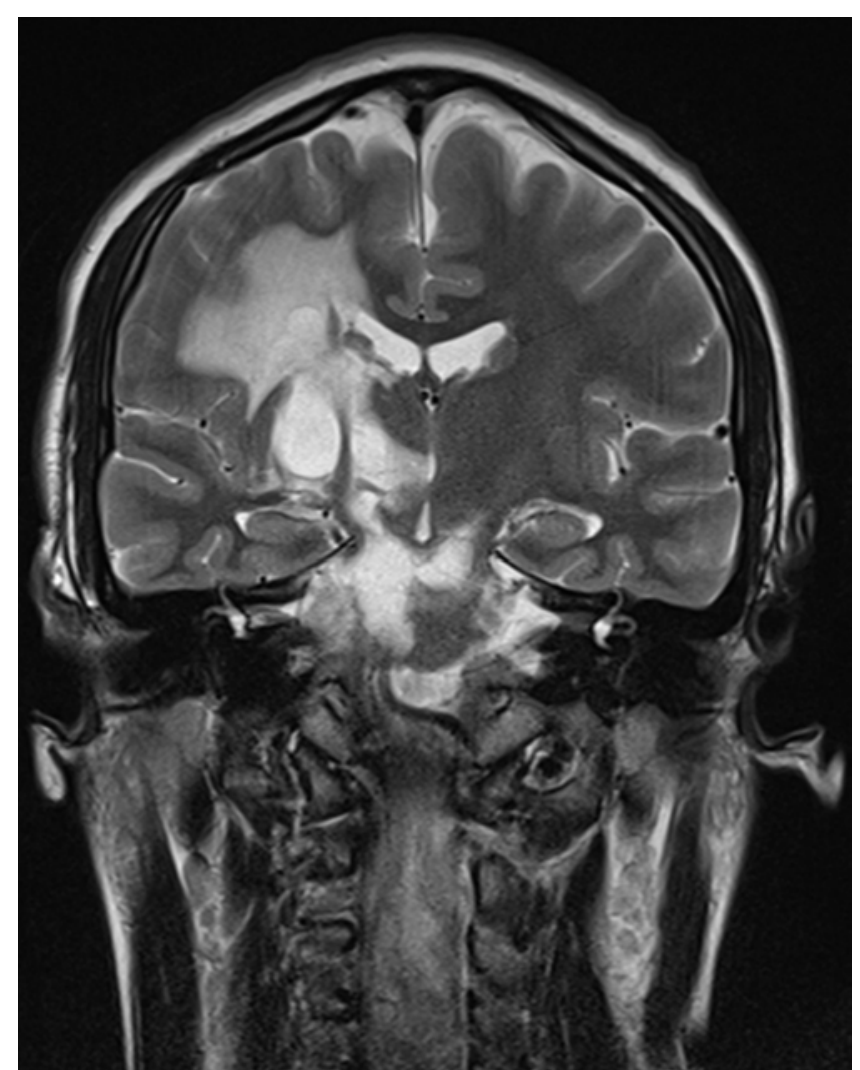

FIG. 3. Preoperative coronal T2-weighted MR image demonstrating cavitation in the pons, right cerebral peduncle, basal ganglia, and central white matter.

hydromyelia (Fig. 5), and the patient was extubated. There was subjective weakness in his left arm and leg for the first 3 days after surgery, which resolved completely. A week after the procedure, MRI showed resolution of the syringocephaly and syringobulbia (Fig. 6). The patient was transferred to a rehabilitation facility from which he was discharged a month later and returned to school. His eating difficulties resolved and his gait normalized. How-

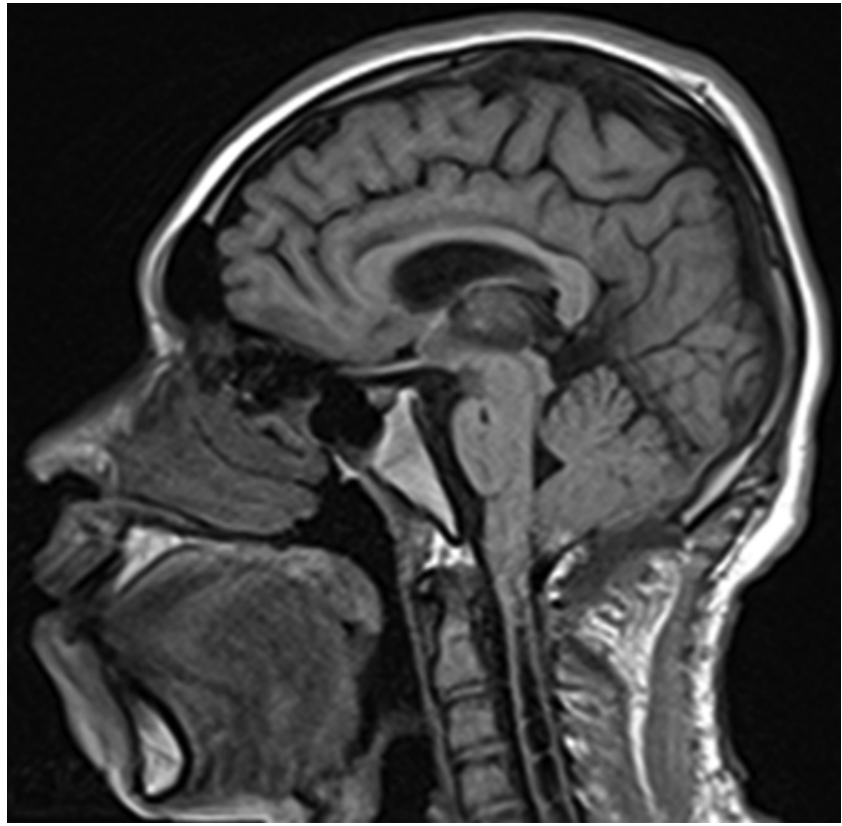

FIG. 5. Midsagittal T1-weighted MR image of the brain and cervical cord obtained 1 day after operation. The syringobulbia was markedly improved.

ever, the pupillary abnormality, hyperreflexia, and left upper extremity sensory deficits persisted at the last followup 15 months after surgery. Magnetic resonance imaging performed at the last follow-up demonstrated resolution of the syringocephaly, syringomesencephaly, syringopontia, and syringobulbia with a marked reduction in the caliber of the cervical syrinx (Fig. 7).

\section{Discussion}

We present a very rare case of massive syringohydromyelia, syringobulbia, and syringocephaly. A 14-year-old boy had neurological deficits at birth with an initial postdelivery diagnosis pointing to spinal cord dysfunction. The diagnosis was confirmed by normal electromyogra-
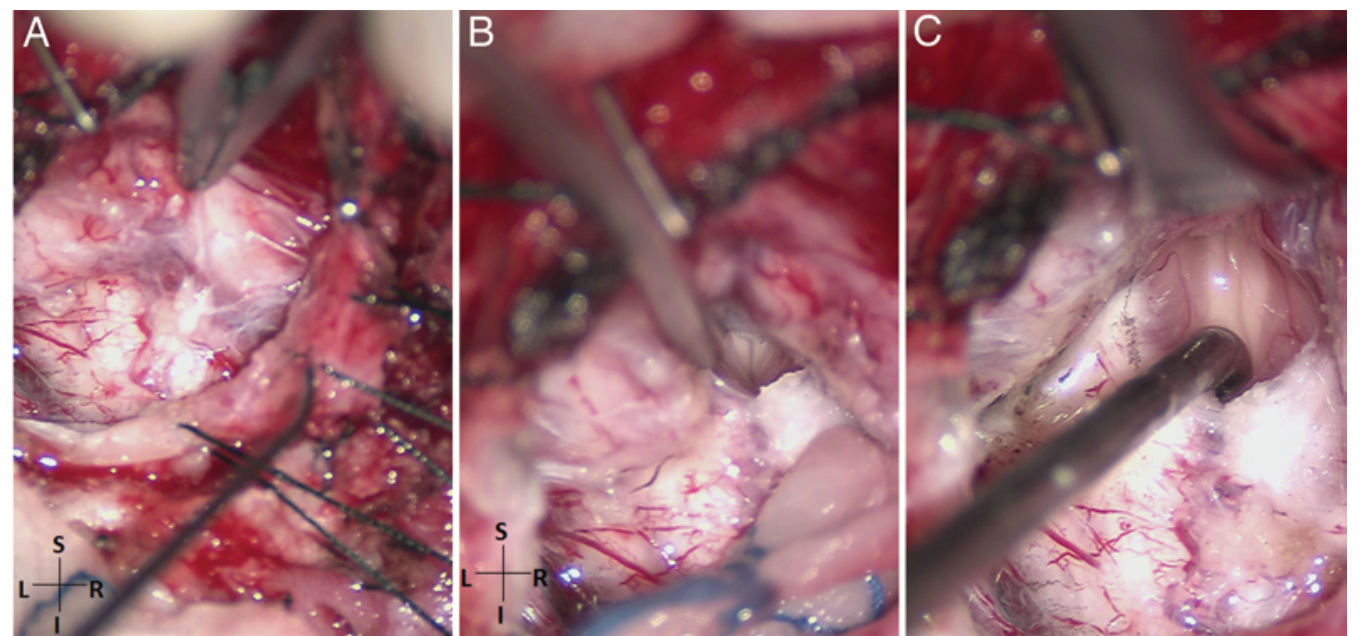

FIG. 4. Operative photograph (A) after posterior fossa dural opening. The opaque arachnoid occludes the foramen of Magendie. Photographs after opening the foramen of Magendie (B) and visualization of the floor of the fourth ventricle (C). The foramen cecum was widely patent. 

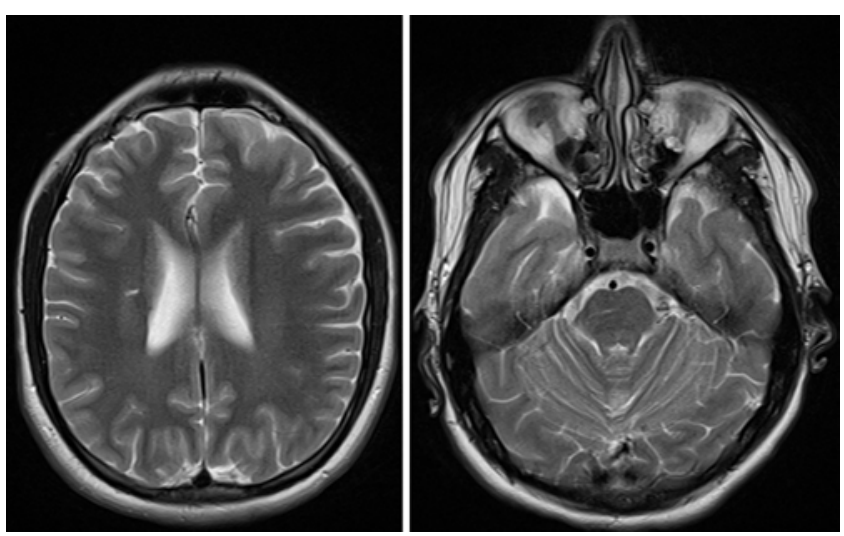

FIG. 6. Composite of axial T2-weighted brain MR images obtained 1 week after operation. The syringocephaly (left) and syringobulbia (right) are represented by very "filamentous" slits.

phy studies, and the condition improved with the passage of time. In 1989 Osenbach and Menezes ${ }^{21}$ identified 32 children in a series of pediatric patients with spinal cord injury without radiographic abnormality, as in our patient. The mechanism of injury in birth trauma was associated with breech presentation and forceps assistance with hyperextension-flexion and distraction in 10 of the patients. ${ }^{15}$ Our patient's neurological symptoms were initially vague but the insensate left arm with the absence of pain sensation was suspicious for a neurogenic cause. The very delayed development of new Horner's syndrome caused reinvestigation through the Neuro-Ophthalmology Service and the recognition of an MRI abnormality.

The first reports of syringobulbia, syringopontia, and syringomesencephalia were all autopsy reports. In 1906 Spiller reported on this combination in the British Medical Journal and described extensive autopsy findings. ${ }^{29}$ Subsequently, Hardy and Stevenson recognized syringomesencephalia in a Parkinson patient who had a syrinx into the substantia nigra. ${ }^{8}$ Samples et al. also reported on syringomesencephalia in the pre-MRI era. ${ }^{25}$ There have been several publications since, $, 2,9,13,23,27$ and a review of the literature was performed by Afifi and Menezes ${ }^{1}$ in 1997 and subsequently by Greenlee et al. in 2005 .
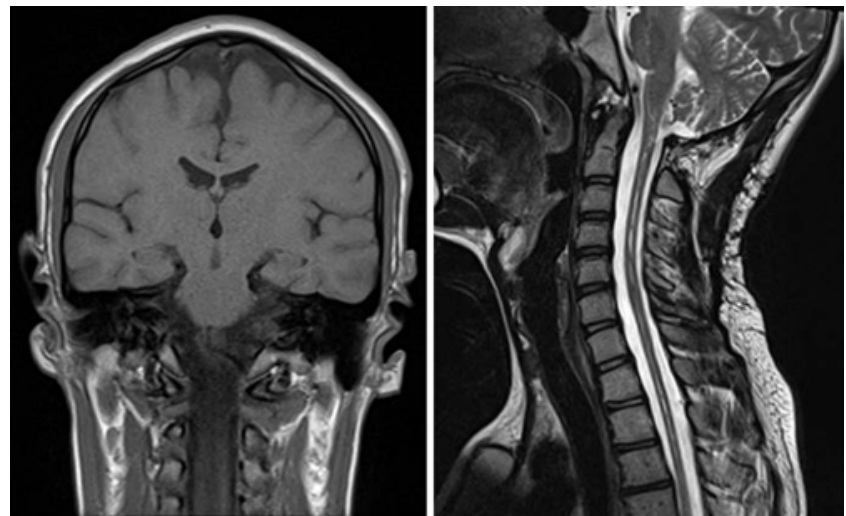

FIG. 7. Coronal T1-weighted brain MR image (left) and midsagittal T2-weighted MR image (right) of the posterior fossa and cervical cord made 15 months postoperatively. These images show resolution of the syringocephaly, syringomesencephaly, syringopontia, and syringobulbia. There was significant improvement in the syringohydromyelia.
Valentini and colleagues detailed an evaluation of 75 patients with syringomyelia, 8 of whom had a syringobulbic extension. ${ }^{34,35}$ In 5 of the 8 patients there was communication with the fourth ventricle, while in the other 3 patients the cavity was in the anterior medulla and pons with a cerebral projection. In several of these cases, contrast material was injected into the ventricle or the syringomyelic cavity to identify the extension. In 1992 Morgan and Williams described 54 patients straddling the arrival of MRI. The patients were separated into 2 categories: ${ }^{16}$ those with a "cleft-like extension" out of the fourth ventricle, which "under pressure" moved upward into the brainstem, and another group without the fourth ventricular cleft where the syrinx was apart from the fourth ventricle but along the anterior aspect of the medulla into the brainstem.

Cranial nerve involvement with CM-I abnormality with or without syringohydromyelia and syringobulbia is very common. ${ }^{10,12,14,16,19,22,30,32,36}$ The most frequently involved cranial nerves are the vagus and hypoglossal, followed by the cranial nerves affecting the ocular motor musculature, especially the abducens and trochlear, as well as the involvement of Horner's syndrome. Trigeminal sensory disturbance and trigeminal neuralgia have also been described.

As regards the patient in the featured case, we feel that the underlying pathology was significant birth trauma with arachnoiditis in the posterior fossa leading to a trapped fourth ventricle. Regression of the supratentorial syrinx cavity immediately postoperatively, followed by regression of the pontine and brainstem component a few days later and subsequent near resolution of the cervical syrinx led us to postulate that the common denominator was the cervical syringohydromyelia with upward extension.

\section{Conclusions}

Syringocephaly is an extremely rare extension of syringomyelia, and our case report suggests that surgical decompression with restoration of CSF flow pathways at the foramen magnum and fourth ventricular outlet is an effective treatment.

\section{References}

1. Afifi AK, Menezes AH: Rostral slit-like extension of holochord syringomyelic cavity: childhood-onset case and review of literature. J Child Neurol 12:515-518, 1997

2. Aryan HE, Yanni DS, Nakaji P, Jandial R, Marshall LF, Taylor WR: Syringocephaly. J Clin Neurosci 11:421-423, 2004

3. Berry RG, Chambers RA, Lublin FD: Syringoencephalomyelia (syringocephalus). J Neuropathol Exp Neurol 40:633644, 1981

4. Chung HD, DeMello DE, D’Souza N, Estrada J: Infantile hypoventilation syndrome, neurenteric cyst, and syringobulbia. Neurology 32:441-444, 1982

5. Del Bigio MR, Deck JH, MacDonald JK: Syrinx extending from conus medullaris to basal ganglia: a clinical, radiological, and pathological correlation. Can J Neurol Sci 20:240246, 1993

6. DiMario FJ, Bauer L, Baxter D: Respiratory sinus arrhythmia of brainstem lesions. J Child Neurol 14:229-232, 1999

7. Greenlee JDW, Menezes AH, Bertoglio BA, Donovan KA: Syringobulbia in a pediatric population. Neurosurgery 57:1147-1153, 2005 
8. Hardy RC, Stevenson LD: Syringomesencephalia; report of a case with signs of Parkinson's disease having a syrinx of the substantia nigra. J Neuropathol Exp Neurol 16:365-370, 1957

9. Heidel KM, Benarroch EE, Gené R, Klein F, Meli F, Saadia $\mathrm{D}$, et al: Cardiovascular and respiratory consequences of bilateral involvement of the medullary intermediate reticular formation in syringobulbia. Clin Auton Res 12:450-456, 2002

10. Jha S, Das A, Gupta S, Banerji D: Syringomyelia with syringobulbia presenting only with paralysis of 9th and 10th cranial nerves. Acta Neurol Scand 105:341-343, 2002

11. Kanev PM, Getch CC, Jallo J, Faerber EN: Cerebral syrinx with Chiari I malformation. Pediatr Neurosurg 20:214-216, 1994

12. Kerrison JB, Biousse V, Newman NJ: Isolated Horner's syndrome and syringomyelia. J Neurol Neurosurg Psychiatry 69:131-132, 2000

13. Lee JH, Chung CK, Kim HJ: Cerebral dissection from syringomyelia demonstrated using cine magnetic resonance imaging. Case report. J Neurosurg 94:318-321, 2001

14. Massey SL, Buland J, Hauber S, Piatt J Jr, Goraya J, Faerber E, et al: Acute VI nerve palsy in a 4 year-old girl with Chiari I malformation and pontomedullary extension of syringomyelia: case report and review of the literature. Eur J Paediatr Neurol 15:303-309, 2011

15. Menezes AH, Osenbach RK: Spinal cord injury, in Cheek WR, Marlin AE, McLoine DG, et al (eds): Pediatric Neurosurgery, ed 3. Philadelphia: WB Saunders, 1994, pp 320-343

16. Morgan D, Williams B: Syringobulbia: a surgical appraisal. J Neurol Neurosurg Psychiatry 55:1132-1141, 1992

17. Muroi A, Syms NP, Oi S: Giant syringobulbia associated with cerebellopontine angle arachnoid cyst and hydrocephalus. J Neurosurg Pediatr 8:30-34, 2011

18. Nagahiro S, Matsukado Y, Kuratsu J, Saito Y, Takamura S: Syringomyelia and syringobulbia associated with an ependymoma of the cauda equina involving the conus medullaris: case report. Neurosurgery 18:357-360, 1986

19. Nogués M, López L, Meli F: Neuro-ophthalmologic complications of syringobulbia. Curr Neurol Neurosci Rep 10:459-466, 2010

20. Okada S, Nakagawa Y, Hirakawa K: Syringomyelia extending to the basal ganglia. Case report. J Neurosurg 71:616617,1989

21. Osenbach RK, Menezes AH: Spinal cord injury without radiographic abnormality in children. Pediatr Neurosci 15:168-175, 1989

22. Pomeranz H: Isolated Horner syndrome and syrinx of the cervical spinal cord. Am J Ophthalmol 133:702-704, 2002

23. Rhoton EL, Rhoton AL Jr: Chiari malformation with syringocephaly. Case report. J Neurosurg 75:791-794, 1991

24. Romero-Pinel L, Fernández S, Torres A, Majós C, Ferran E, Martínez-Yélamos S, et al: Syringomyelia extending to the corona radiata. J Neurol 253:817-818, 2006

25. Samples JR, Howard FM Jr, Okazaki H: Syringomesencephalia. Report of a case. Arch Neurol 40:757-759, 1983
26. Sarikaya S, Acikgöz B, Tekkök IH, Güngen YY: Conus ependymoma with holocord syringohydromyelia and syringobulbia. J Clin Neurosci 14:901-904, 2007

27. Sengar RLS, Prasad VSSV, Prasad BCM, Reddy DR: Giant syringobulbia in childhood. Childs Nerv Syst 10:350-351, 1994

28. Shuster A, Landry D: Case 191: giant hemorrhagic syringomyelia and syringobulbia mimicking intramedullary neoplasm. Radiology 266:991-993, 2013

29. Spiller WG: Syringomyelia, extending from the sacral region of the spinal cord through the medulla oblongata, right side of the pons and right cerebral peduncle to the upper part of the right internal capsule (syringobulbia). Br Med J 2:10171021, 1906

30. Stovner LJ, Kruszewski P, Shen JM: Sinus arrhythmia and pupil size in Chiari I malformation: evidence of autonomic dysfunction. Funct Neurol 8:251-257, 1993

31. Sundaram SS, Vijeratnam D, Mani R, Gibson D, Chauhan AJ: Tuberculous syringomyelia in an HIV-infected patient: a case report. Int J STD AIDS 23:140-142, 2012

32. Trobe JD: The evaluation of horner syndrome. J Neuroophthalmol 30:1-2, 2010

33. Tubbs RS, Bailey M, Barrow WC, Loukas M, Shoja MM, Oakes WJ: Morphometric analysis of the craniocervical juncture in children with Chiari I malformation and concomitant syringobulbia. Childs Nerv Syst 25:689-692, 2009

34. Valentini MC, Bracchi M, Gaidolfi E, Savoiardo M: Radiologic demonstration of syringobulbia. Report of 8 cases. Acta Radiol Suppl 369:245-247, 1986

35. Valentini MC, Forni C, Bracchi M: Syringobulbia extending to the basal ganglia. AJNR Am J Neuroradiol 9:205-207, 1988

36. Viswanatha B: Syringomyelia with syringobulbia presenting as vocal fold paralysis. Ear Nose Throat J 88:E20, 2009

37. Weese-Mayer DE, Brouillette RT, Naidich TP, McLone DG, Hunt CE: Magnetic resonance imaging and computerized tomography in central hypoventilation. Am Rev Respir Dis 137:393-398, 1988

\section{Author Contributions}

Conception and design: Menezes, Hansen. Acquisition of data: Menezes, Hansen, Abode-Iyamah. Analysis and interpretation of data: Menezes, Greenlee. Drafting the article: Menezes, Greenlee, Longmuir. Critically revising the article: Menezes, Greenlee, Longmuir. Reviewed submitted version of manuscript: all authors. Approved the final version of the manuscript on behalf of all authors: Menezes. Administrative/technical/material support: Menezes, Hansen. Diagnostics: Longmuir.

\section{Correspondence}

Arnold H. Menezes, Department of Neurosurgery, University of Iowa Hospitals and Clinics, 200 Hawkins Dr., 1824 JPP, Iowa City, IA 52242.email: arnold-menezes@uiowa.edu. 